\title{
Sex Specific Transcriptional Regulation of Gonadal Steroidogenesis in Teleost Fishes
}

\author{
Partigya Sharma, Shriya Purohit, Sachin Kothiyal, Shilpa Negi \\ and Indrashis Bhattacharya* \\ Department of Zoology, Hemvati Nandan Bahuguna (HNB) Garhwal University, Pauri Garhwal, India
}

Keywords: transcription factor, steroidogenesis, testosterone, estrogen, cortisol

\section{INTRODUCTION}

OPEN ACCESS

Edited by:

Mohd Ashraf Rather,

Sher-e-Kashmir University of

Agricultural Sciences \&

Technology of Kashmir, India

Reviewed by:

Aritra Bera,

Central Institute of Brackishwater

Aquaculture (ICAR), India

Carlos Alfonso Alvarez-González,

Universidad Juárez Autónoma de

Tabasco, Mexico

*Correspondence:

Indrashis Bhattacharya

indrashis.bhattacharya@gmail.com

Specialty section: This article was submitted to Experimental Endocrinology, a section of the journal

Frontiers in Endocrinology

Received: 22 November 2021 Accepted: 10 January 2022 Published: 18 February 2022

Citation: Sharma P, Purohit S, Kothiyal S, Negi S and Bhattacharya I (2022)

Sex Specific Transcriptional

Regulation of Gonadal

Steroidogenesis in Teleost Fishes.

Front. Endocrinol. 13:820241. doi: 10.3389/fendo.2022.820241
Fishes are developmentally diverse and economically essential organisms (1). Teleost fishes show remarkable gonadal plasticity by representing both gonochorism (one sex at a time) and hermaphroditism (more than one sex) (1-3). Gonochoristic teleosts mature as either males or females and remain in such sexual identity throughout adulthood, whereas hermaphroditic species are plastic in terms of sex-reversal signals, i) protogynous (female to male e.g. gilt-head sea bream Sparus auratus, bluehead wrasse Thalassoma bifasciatum), ii) protandrous (male to female e.g. clown fish Amphiprion sp, Premnas sp, Rice filed eel Monopterus albus and black porgy Acanthopagrus schlegeli) or iii) in both directions for multiple times (e.g. Okinawa goby Trimma okinawae, cleaner wrasse Labroides dimidiatus and monogamous coral-dwelling gobies Paragobiodon and Gobiodon) $(1,4)$. Sexual identity is controlled by social cues and environmental stimuli that operate via the cross-talk between hypothalamus-pituitary-gonadal (HPG) and hypothalamus-pituitary- inter-renal (HPI) axes involving neuro-endocrine factors like kisspeptin, dopamine, gonadotropin- releasing hormone $(\mathrm{GnRH})$, gonadotropins (FSH and LH) and gonadal steroids like $17 \beta$-estradiol $\left(\mathrm{E}_{2}\right)$ and testosterone $(\mathrm{T})(5-7)$. Gonadal cells initiate the steroidogenic cascade under the influence of FSH and LH by transporting cholesterol from cytosolic lipid droplet to mitochondrial inner membrane via Steroidogenic acute regulatory protein (StAR) followed by its rate limited conversion to pregnenolone via P450scc enzyme (Cholesterol side chain cleavage enzyme) coded by Cyp11a1 gene (8). Pregnenolone then gets converted to T through multiple steps prior to the synthesis of bio-active male androgen i.e. 11-Keto-Testosterone (11-KT) or female specific $\mathrm{E}_{2}$. The production of $\mathrm{E}_{2}$ from $\mathrm{T}$ depends on P450- aromatase enzyme coded by Cyp19a1a gene in ovaries whereas, T gets converted to 11- hydroxy-androstenedione (11-OHA) by $11 \beta$-hydroxylase enzyme coded by Cyp $11 b$ gene and subsequently $11-\mathrm{OHA}$ acts as a substrate for $11 \beta$-hydroxysteroid dehydrogenase (11 $\beta$-HSD) enzyme coded by Hsd11b2 gene to produce 11-KT in testes $(1,6-8)$.

Experimental feminization of XY fries and/or masculinization of XX fries have been successfully achieved by administration of exogenous $\mathrm{E}_{2}$ or $\mathrm{T}$ for two months respectively $(9,10)$ despite having a robust genetic mechanism for sex determination (GSD) in medaka Oryzias latipes $(11,12)$. Furthermore, long term depletion of endogenous P450 aromatase by fadrozole in adult teleosts like mekada (13), Nile-tilapia Oreochromis niloticus (14) or zebra-fish Danio rerio (15) results into functional female to male sex reversal. Consistently, a dramatic shift in plasma sex steroids also has been reported during gonadal trans-differentiation observed in natural sex changing fishes (3). For 
example, in protogynous species a severe decline in $\mathrm{E}_{2}$ leads to ovarian regression followed by a gradual elevation in circulatory $11-\mathrm{KT}$, whereas in protandrous fishes $\mathrm{E}_{2}$ concentration rises with the decline of $11-\mathrm{KT}$ level $(2,16)$. However, in bidirectional sex change, only $\mathrm{E}_{2}$ (not 11-KT) shows such sexual shift in the circulatory pattern $(2,16)$. Therefore, the critical balance between the bio-conversion rates of $\mathrm{T}$ to either $\mathrm{E}_{2}$ or 11-KT exclusively directs the sexual fate, reproductive maturation and fertility potential in fishes. The seasonal reproductive cyclicity of fishes is broadly categorized into five stages i) Resting Phase ii) Preparatory/ Recrudescence Phase iii) Pre-Spawning/Developing Phase iv) Spawning Active/Capable Phase v) Post-Spawning/Regressing/ Spent Phase (17). Intriguingly, a drastic steroidogenic shift occurs in post-vitellogenic (Spawning Phase) ovaries during meiotic maturation of oocytes involving an inhibition of FSH signal leading to the suppression of Cyp19a1a promoter and thereby decline in $\mathrm{E}_{2}$ production with subsequent $\mathrm{LH}$ mediated activation of $20 \beta$ - $H s d$ promoter for the production of maturation inducing steroids $[17 \alpha, 20 \beta$-DPs $(17 \alpha, 20 \beta$-dihydroxy-4-pregnen3 -one or $17 \alpha, 20 \beta, 21$-trihydroxy-4-pregnen-3-one)] $(6,8,18)$. Similarly, a dominant upregulation of $\mathrm{Hs} d 11 \mathrm{b2}$ promoter activity has been reported in testes ensuring the rise in 11-KT level in spawning males. Therefore, a complex interplay among the multiple cis acting sequences/elements and respective trans acting factors collectively regulate the sex specific differential promoter activities of the genes coding for key steroidogenic enzymes in teleost gonads (8). Although brain, kidney, liver and adipose tissues are other potential sites of steroidogenesis in fishes, we here briefly highlight the critical contribution of major transcription factors regulating gonadal steroidogenic output to determine fish reproduction.

\section{GLUCOCORTICOID RECEPTORS}

Corticosteroid like cortisol produced from adrenal glands acts via glucocorticoid receptor (GR) and critically regulates the promoter function of Cyp19a1a and Cyp11c1/Cyp11b or $H s d 11 b 2$ genes thereby fixing the $\mathrm{E}_{2}$ : $11-\mathrm{KT}$ concentration (2, 5). Cortisol induced GR blocks the aromatase enzyme in the ovaries of pejerrey Odontesthes bonariensis (19) or Japanese flounder Paralichthys olivaceus (20) and induces the promoter activity of $H s d 11 b 2$ in the testes of pejerrey (21) or European eel Anguilla anguilla (22) in male favourable temperatures.

\section{FOXL $_{2}$}

$\mathrm{FOXL}_{2}$ (Forkhead transcription factor 2), member of the winged helix/fork-head group of proteins is known for ovarian differentiation (23). Fox genes like Foxc1, Foxl $2, F_{0 x l}$ (a germ cell intrinsic transcription factor determinant of sexual fate in medaka) have been shown to determine the ovarian function (23). In ovary, $\mathrm{FOXL}_{2}$ suppresses Dmrt1 and upregulates female programming genes like Cyp19a1a, Rspo1 and Wnt4/Bcatenin etc and support $\mathrm{E}_{2}$ production $(23,24)$. The co-localizations of $\mathrm{FOXL}_{2}$ and $\mathrm{P} 450$ aromatase enzyme in the ovaries of adult medaka (25), Nile-tilapia (26-29) and Japanese flounder (30) suggest the critical involvement of $\mathrm{FOXL}_{2}$ in transcriptional regulation of Cyp19a1a and $\mathrm{E}_{2}$ production. In medaka, $\mathrm{FOXL}_{2}$ protein is initially detected in the germline stem cells and maintained thereafter throughout the meiotic progression (23). In Nile-tilapia, the promoter region of Cyp19ala possesses the core element ACAAATA from -545 to -538 known for the binding site for $\mathrm{FOXL}_{2}$ (27). Over-expression of $\mathrm{Foxl}_{2}$ dominant negative mutant in $\mathrm{XX}$ tilapia triggers female to male reversal (27), whereas the loss of Foxl 2 in XX tilapia leads to female to male reversal $(27,31-33)$. In Japanese flounder $\mathrm{FOXL}_{2}$ directly activates the Cyp19ala gene transcription by binding to the forkhead- responsive site (30).

\section{AD4BP/SF-1}

Ad4 Binding Proteins/Steroidogenic Factor1 (AD4BP/SF-1) or Fushi Tarazu factor 1 (FTZ-F1) is an orphan nuclear receptor under subfamily 5 group A member 1 (NR5A1) that gets colocalized in the interstitial cells of pre-vitellogenic ovary and granulosa cells of the vitellogenic follicles along with $\mathrm{FOXL}_{2}$ and P450 aromatase in medaka $(34,35)$ and Nile-tilapia (27). Although in TM3 cell lines and granulosa cells of Nile-tilapia, $\mathrm{FOXL}_{2}$ alone can activate the gene transcription of Cyp19a1a as both these cells contain endogenous Ad4BP/SF-1, FOXL 2 alone fails to show such impact on the Cyp19a1a promoter in HEK293 cells (27). However, with co-transfection of $A d 4 B P / S F 1$ and $\mathrm{Foxl}_{2}$, the $\mathrm{P} 450$ aromatase promoter gets pronouncedly activated indicating $F o x l_{2}$ and $A d 4 B P / S F 1$ act synergistically to augment Cyp19a1a transcription (36). On the other hand, $A d 4 B P / S F-1$ binds to two FF1 response elements on the promoter of Cyp11a1 gene and upregulates its transcription in zebra-fish (37).

\section{DAX1}

DAX1 (Dosage- sensitive sex reversal adrenal hypoplasia congenital critical region on the $\mathrm{X}$ chromosome, gene 1), an orphan receptor is a member of the nuclear receptor superfamily (NR0B1). Dax1 is expressed in adrenal cortex, gonads, ventromedial hypothalamus and pituitary gonadotrophs potentially crucial for testis differentiation (38-40). The expression of Dax1 is up-regulated by androgen in rainbow trout Oncorhynchus mykiss during ovary to testis transition (41). In medaka, DAX1 has only one LXXLL- related motif in Nterminal and is involved in repressing $\mathrm{E}_{2}$ synthesis in ovarian follicles (36). In medaka co-transfection of Dax1 along with $A D 4 B P / S F-1$ and $F_{0 x l}$ in a dose dependent manner leads to a significant decline in the activity of Cyp19a1a promoter indicating that DAX1 negatively regulates Cyp19a1a expression by suppressing $\mathrm{Ad} 4 \mathrm{BP} / \mathrm{SF} 1$ and $\mathrm{FOXL}_{2}$ proteins in ovarian follicles (36). 


\section{DMY/DMRT 1}

In metazoans, double-sex and mab-3 related transcription factor 1 (Dmrt1) is the critical inducer of testicular differentiation (42). Testes restricted expression patterns of Dmrt1 have been found in medaka, Nile-tilapia, Olive flounder, Rainbow trout African catfish Clarias gariepinus, rare minnow Gobiocypris rarus, lake sturgeon Acipenser fulvescens, Atlantic cod Gadus morhua, pejerrey,shovelnose sturgeon Scaphirhynchus platorynchus and southern catfish Silurus meridionals (42). DMRT1 either alone or in synergy with DAX1 represses the female programming genes like Cyp19a1a, Rspo1, Figla, Gdf9 and Wnt4/ $\beta$ catenin and augments the transcription of male specific genes like Gsdf, Cyp11c1, Sox9/3, Amh etc in testes (42). The exposure of $\mathrm{E}_{2}$ downregulates Dmrt1 transcription in medaka (43), African catfish (44), Nile-tilapia (28), rare minnow (45), pejerrey (46), zebra-fish (47) and rainbow trout (48). DMRT1 directly suppresses Cyp19a1a promoter activity in medaka (36) and in Nile-tilapia (28). In XX tilapia, overexpression of Dmrt1 leads to downregulation of Cyp19a1a expression and $\mathrm{E}_{2}$ production (28). However, knock-down of Dmrt1 in XY tilapia (32) and mutation of Dmrt1 in Cynoglossusse milaevis (49) resulted in increased $\mathrm{Foxl}_{2}$ and Cyp19ala expression without any male to female sex reversal. On the other hand, the loss of Dmrt1 leads to an elevated expression of $\mathrm{Foxl}_{2}$ in zebra-fish (50) whereas an augmentation in both Foxl 2 and Cyp19ala in medaka (51). The duplicated copy of Dmrt1a on the Y chromosome Dmy/ Dmrt1bY (DM domain gene on the Y chromosome/doublesex and mab-3 related transcription factor $1 \mathrm{~b}$ on the $\mathrm{Y}$ chromosome) acts as a master of male sex in medaka $(12,52)$. However, Dmy downregulates itself by binding to the conserved cis-regulatory elements like Izanagi, within its promoter (42). In differentiating testes of medaka, Dmy downregulates the hedgehog pathway by suppressing its receptor Pitch-2 and upregulating its antagonist Hhip (42).

\section{SOX PROTEINS}

The Sry related HMG box (Sox) gene(s) encode variety of transcription factor(s) critical for gonadal morphogenesis (5). Two paralogous forms of Sox9, namely Sox9a and Sox9b are reported in medaka and zebra-fish without any such sexual dimorphic expression pattern (53). In Indian rice-fish Oryzias dancena, Sox3 gene has been shown critical for sex determination by up-regulating expression of Gsdf (Gonadal soma-derived factor) (54). The expressions of Sox3 and Hsd11b2 are found to be associated with the initiation and progression of spermatogenesis in male catfish testis (8). Precisely, SOX3 binds to Hsd11b2 gene promote and transactivates its transcription in males (8). During development of zebra-fish, the transcription factor SOX5, directly downregulates the Dmrt1 transcription (42) whereas SOX5 downregulates Cyp19a1a transcription in the red spotted grouper Epinephelus akaara (55).

\section{OTHER TRANSCRIPTION FACTORS}

Wilm's tumor 1 (WT1) is a key transcription factor having critical role in mammalian gonadal morphogenesis (5). In Indian catfish Clarias batrachus, WT1 has been shown to upregulate the promoter activity of $H s d 11 b 2$ (56). E 2 bound Estrogen Receptor (coded by Esrl gene) acts as a potential transcriptional inducer for Cyp19a1a in zebra-fish $(57,58)$. Finally, activated cAMP response element binding protein (CREB-P; phosphorylated at Ser-133 residue) differentially regulate the transcriptional control of Cyp19a1a and 20 - -Hsd genes as found in ovaries of Niletilapia, rainbow trout and catfishes $(8,18)$. In pre-spawning vitellogenic ovaries, CREB-P upregulates the transcription of Cyp19a1a in synergy with Ad4BP/SF-1 and FOXL 2 under the influence of FSH. However, in post-vitellogenic spawning ovaries such dominant transcription of Cyp19ala gets downregulated due to selective inhibition of FSH signal followed by LH induced upregulation $20 \beta$-Hsd transcription by CREB-P alone synthesizing maturation inducing steroids (17 $\alpha, 20 \beta-D P s)$ critical for the meiotic progression of developing oocytes $(8,18)$.

\section{CONCLUSION}

In summary, molecular techniques like Electrophoretic mobility shift assay (EMSA) or Chromatin immuno-precipitation (ChIP) assay investigating DNA-protein interactions have revealed the differential promoter activities of the key steroidogenic genes like $C y p 19 a 1 a, C y p 11 b$ and $H s d 11 b 2$ by various transcription factors to regulate the turnover rate of $\mathrm{T}$ for fixing the $\mathrm{E}_{2}$ : $11-\mathrm{KT}$ concentration in fish gonads (8). For example, in males, DMRT1 directly suppresses Cyp19a1a transcription, while DAX1 does the same via inhibiting $\mathrm{FOXL}_{2}$ and $\mathrm{Ad} 4 \mathrm{BP} / \mathrm{SF}-1$ leading to the testicular differentiation. Conversely, FOXL 2 and Ad4BP/SF-1 augment the expression of Cyp 19a1a ensuring $\mathrm{E}_{2}$ production and promote the ovarian function. Figure 1 schematically represents the complex antagonistic genetic network that regulates the ovarian estrogenic or testicular androgenic milieu in teleost gonads. Supplementary Table 1 describes the critical role(s) of major transcription factors identified till date in different teleost species in a chronological order directing gonadal development and function. Supplementary Table 2 summarizes the effect of various environmental parameters on fish gonadal development and steroidogenesis.

\section{FUTURE DIRECTIONS}

Notably there is a potential scope for the commercial application of genetically engineered fishes having mutant transcription factors by advanced genome editing technologies like TALEN/CRISPERCAS9 Transgenesis/RNAi mediated silencing etc. These gain in function (by transgenic over-expression/integration) or loss of function (by knock-out/down) models can be successfully implemented in aquaculture or fishery industry to increase the productivity/yield by manipulating fertility offishes. However more studies are required in non-model teleost species by employing 


\begin{tabular}{|c|c|c|c|c|c|}
\hline Name of the Enzyme & Gene & $\begin{array}{c}\text { Sexual Dimorphic } \\
\text { pattern }\end{array}$ & Function & Inducer & Repressor \\
\hline P450-Aromatase & Cyplaala & Female Specific & $\begin{array}{l}\text { Converts Testosterone into } \\
\text { Estrogen }\end{array}$ & Foxl $_{2}$,Ad4BP/SF1 & Dmrt1,Dax1,Dmy,Sox3,Sox9 \\
\hline $11 \beta$-hydroxylase & Cyp11b & Male Specific & $\begin{array}{c}\text { Converts Testosterone into 11- } \\
\text { hydroxy-androstenedione(11-OHA) }\end{array}$ & Dmrt1,Dmy,Sox3,Sox9 & Foxl $_{2}$,Ad4BP/SF1 \\
\hline $\begin{array}{l}\text { 11ß-hydroxysteroid } \\
\text { dehydrogenase }\end{array}$ & $11 \beta-H s d$ & Male Specific & 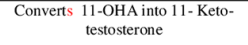 & Dmrt1,Dmy, Sox3,Sox9 & $\mathrm{Foxl}_{2}, \mathrm{Ad} 4 \mathrm{BP} / \mathrm{SF} 1$ \\
\hline
\end{tabular}

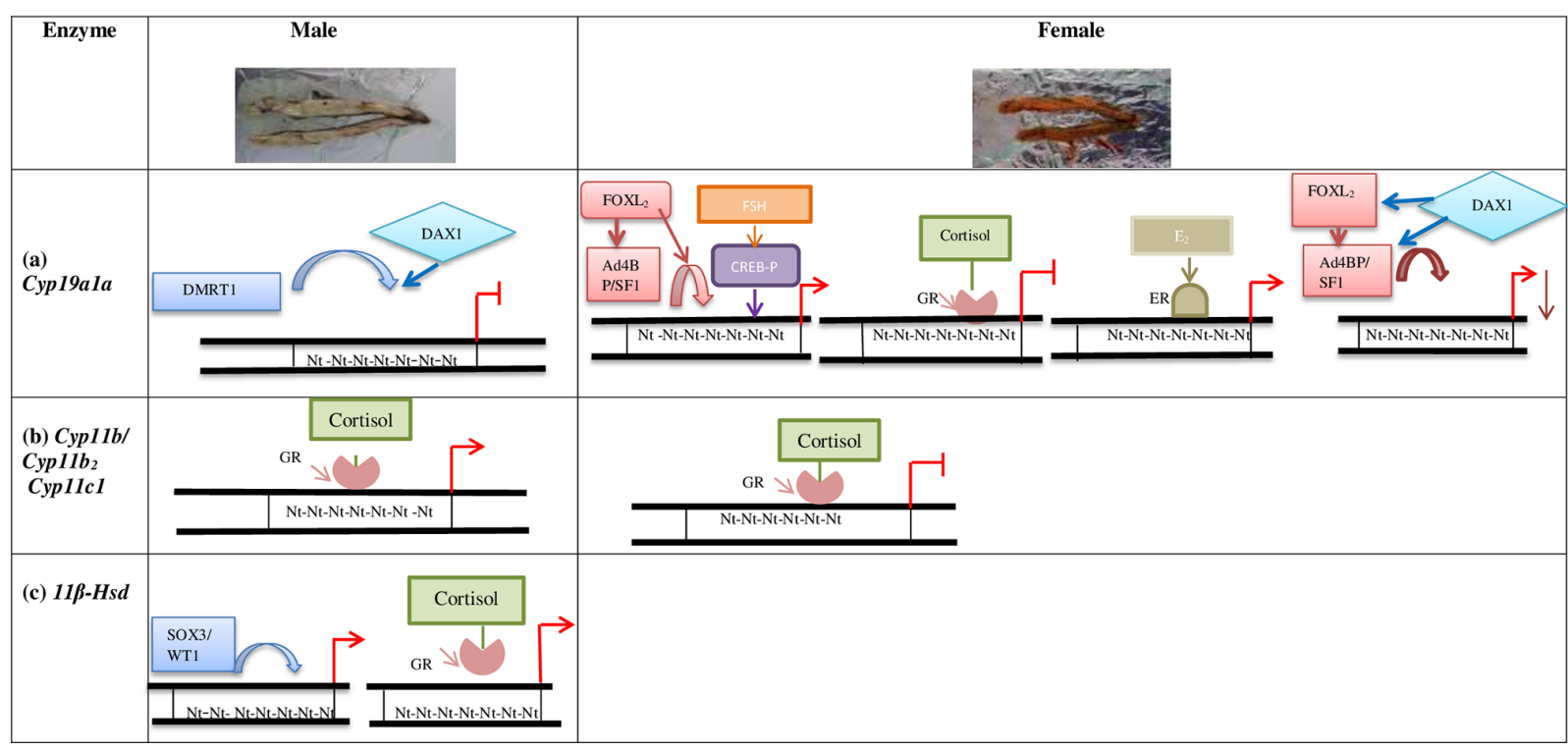

FIGURE 1 | Sex specific regulation of gonadal steroidogenesis by transcription factors. Images of testis and ovary are representatives of a typical fresh water teleost (Schizothorax plagiostomus, Order: Cypriniformes, Family: Cyprinidae). (A) Regulation of Cyp19a1a promoter: In testis, DMRT1 alone or in synergy with DAX1 represses the Cyp19a1a transcription. In ovaries, FOXL 2 either alone or along with Ad4BP/SF-1 activates Cyp19a1a transcription. CREB-P upregulates the transcription of Cyp19a1a in synergy with FOXL 2 and Ad4BP/SF1 under the influence of FSH. Cortisol induced Glucocorticoid Receptor (GR) blocks the aromatase enzyme. Estrogen bound Estrogen Receptor (ER) acts as a potential inducer of Cyp19a1a transcription. DAX1 negatively regulates the Cyp19a1a expression by suppressing Ad4BP/SF-1 and FOXL 2 (B) Regulation of Cyp11b/Cyp11b/Cyp11c1 promoters: Cortisol induced GR activates the transcription of Cyp11b/Cyp11b/ Cyp11c1 in males. (C) Regulation of $11 \beta$ - Hsd promoter: In males, SOX3NT1 binds to $11 \beta$-Hsd and promoters its transcription and Cortisol induced GR activates the transcription of $11 \beta-H s d$. $\Gamma$ : Repression $\gg$ : Activation $\gg \downarrow$ : Decline in activity, Nt, Nucleotide sequence.

advanced high throughput next generation sequencing with multiomics approach to generate gonadal transcriptomic resource datasets. This may further help identify the involvement of new putative factor(s) like chromatin remodelling complexes, DNAmethyl-transferases (DNMTs) and novel micro-RNAs or longnon-coding RNAs which can potentially regulate the sex specific transcriptional switch in gonadal steroidogenesis (59).

\section{AUTHOR CONTRIBUTIONS}

IB conceived the idea. PS wrote the first draft of the Text, Figure, and Table with support from SP, SK and SN. IB generated the final form of the manuscript. All authors contributed to the article and approved the submitted version.

\section{FUNIDNG}

IB acknowledges the financial support from University Grants Commission (F.30104/2015BSR) and Department of Science and Technology (ECR/2018/000868). The funder was not involved in the study design, collection, analysis, interpretation of data, the writing of this article or the decision to submit it for publication.

\section{ACKNOWLEDGMENTS}

The authors are sincerely grateful to the Hon'ble Vice Chancellor, HNBGU, Research and Consultancy Coordination cell, HNBGU and past and present Head(s), Dept. of Zoology, HNBGU for valuable support.

\section{SUPPLEMENTARY MATERIAL}

The Supplementary Material for this article can be found online at: https://www.frontiersin.org/articles/10.3389/fendo.2022. 820241/full\#supplementary-material 


\section{REFERENCES}

1. Devlin RH, Nagahama Y. Sex Determination and Sex Differentiation in Fish: An Overview of Genetic, Physiological, and Environmental Influences. Aquaculture (2002) 208(3-4):191-364. doi: 10.1016/S0044-8486(02)00057-1

2. Todd EV, Liu H, Muncaster S, Gemmell NJ. Bending Genders: The Biology of Natural Sex Change in Fish. Sexual Development: Genet Mol Biol Evol Endocrinol Embryol Pathol Sex Determination Differentiation (2016) 10 (5-6):223-41. doi: 10.1159/000449297

3. Bhattacharya I, Modi D. Sex Determination in Teleost Fish. In: Recent Updates in Molecular Endocrinology and Reproductive Physiology of Fish. Singapore: Springer (2021). p. 121-38.

4. DeFalco T, Capel B. Gonad Morphogenesis in Vertebrates: Divergent Means to a Convergent End. Annu Rev Cell Dev Biol (2009) 25:457-82. doi: 10.1146/ annurev.cellbio.042308.13350

5. Capel B. Vertebrate Sex Determination: Evolutionary Plasticity of a Fundamental Switch. Nat Rev Genet (2017) 18(11):675-89. doi: 10.1038/ nrg. 2017.60

6. Tenugu S, Pranoty A, Mamta SK, Senthilkumaran B. Development and Organisation of Gonadal Steroidogenesis in Bony Fishes-A Review. Aquaculture Fisheries (2021) 6(3):223-46. doi: 10.1016/j.aaf.2020.09.004

7. Young G, Kusakabe M, Nakamura I, Lokman PM, Goetz FW. Gonadal Steroidogenesis in Teleost Fish. Mol Aspects Fish Marine Biol (2005) 2:155223. doi: 10.1142/9789812569189_0006

8. Rajakumar A, Senthilkumaran B. Steroidogenesis and its Regulation in Teleost-a Review. Fish Physiol Biochem (2020) 46(3):803-18. doi: 10.1007/ s10695-019-00752-0

9. Yamamoto T. Artificial Induction of Functional Sex-Reversal in Genotypic Females of the Medaka (Oryzias Latipes). J Exp Zool (1958) 137(2):227-63. doi: 10.1002/jez.1401370203

10. Yamamoto TO. 3 Sex Differentiation. In: Fish Physiology, vol. 3. Srinagar, Garhwal: Academic Press (1969). p. 117-75. doi: 10.1016/S1546-5098(08) 60113-2

11. Aida T. On the Inheritance of Color in a Fresh-Water Fish, APLOCHEILUS LATIPES Temmick and Schlegel, With Special Reference to Sex-Linked Inheritance. Genetics (1921) 6(6):554-73. doi: 10.1093/genetics/6.6.554

12. Matsuda M, Nagahama Y, Shinomiya A, Sato T, Matsuda C, Kobayashi T, et al. DMY Is a Y-Specific DM-Domain Gene Required for Male Development in the Medaka Fish. Nature (2002) 417(6888):559-63. doi: 10.1038/nature751

13. Paul-Prasanth B, Bhandari RK, Kobayashi T, Horiguchi R, Kobayashi Y, Nakamoto M, et al. Estrogen Oversees the Maintenance of the Female Genetic Program in Terminally Differentiated Gonochorists. Sci Rep (2013) 3:2862. doi: $10.1038 /$ srep02862

14. Sun LN, Jiang XL, Xie QP, Yuan J, Huang BF, Tao WJ, et al. Transdifferentiation of Differentiated Ovary Into Functional Testis by Long-Term Treatment of Aromatase Inhibitor in Nile Tilapia. Endocrinology (2014) 155(4):1476-88. doi: 10.1210/en.2013-1959

15. Takatsu K, Miyaoku K, Roy SR, Murono Y, Sago T, Itagaki H, et al. Induction of Female-to-Male Sex Change in Adult Zebrafish by Aromatase Inhibitor Treatment. Sci Rep (2013) 3:3400. doi: 10.1038/srep03400

16. Frisch A. Sex-Change and Gonadal Steroids in Sequentially-Hermaphroditic Teleost Fish. Rev Fish Biol Fisheries (2004) 14(4):481-99. doi: 10.1007/s11160005-3586-8

17. Brown-Peterson NJ, Wyanski DM, Saborido-Rey F, Macewicz BJ, LowerreBarbieri SK. A Standardized Terminology for Describing Reproductive Development in Fishes. Marine Coastal Fisheries (2011) 3(1):52-70. doi: 10.1080/19425120.2011.555724

18. Senthilkumaran B. Recent Advances in Meiotic Maturation and Ovulation: Comparing Mammals and Pisces. Front Biosci (Landmark Edition) (2011) 16:1898-914. doi: $10.2741 / 3829$

19. Hattori RS, Fernandino JI, Kishii A, Kimura H, Kinno T, Oura M, et al. Cortisol-Induced Masculinization: Does Thermal Stress Affect Gonadal Fate in Pejerrey, a Teleost Fish With Temperature-Dependent Sex Determination? PloS One (2009) 4(8):e6548. doi: 10.1371/journal.pone.0006548

20. Yamaguchi T, Yoshinaga N, Yazawa T, Gen K, Kitano T. Cortisol Is Involved in Temperature-Dependent Sex Determination in the Japanese Flounder. Endocrinology (2010) 151(8):3900-8. doi: 10.1210/en.2010-0228
21. Fernandino JI, Hattori RS, Kishii A, Strüssmann CA, Somoza GM. The Cortisol and Androgen Pathways Cross Talk in High Temperature-Induced Masculinization: The 11 $\beta$-Hydroxysteroid Dehydrogenase as a Key Enzyme. Endocrinology (2012) 153(12):6003-11. doi: 10.1210/en.2012-1517

22. Geffroy B, Bardonnet A. Sex Differentiation and Sex Determination in Eels: Consequences for Management. Fish Fisheries (2016) 17(2):375-98. doi: 10.1111/faf.12113

23. Bertho S, Pasquier J, Pan Q, Le Trionnaire G, Bobe J, Postlethwait JH, et al. Foxl2 and Its Relatives Are Evolutionary Conserved Players in Gonadal Sex Differentiation. Sexual Development: Genet Mol Biol Evol Endocrinol Embryol Pathol Sex Determination Differentiation (2016) 10(3):111-29. doi: 10.1159/ 000447611

24. Nishimura T, Tanaka M. The Mechanism of Germline Sex Determination in Vertebrates. Biol Reprod (2016) 95(1):30. doi: 10.1095/biolreprod.115.138271

25. Nakamoto M, Matsuda M, Wang DS, Nagahama Y, Shibata N. Molecular Cloning and Analysis of Gonadal Expression of Foxl2 in the Medaka, Oryzias Latipes. Biochem Biophys Res Commun (2006) 344(1):353-61. doi: 10.1016/ j.bbrc.2006.03.137

26. Wang D, Kobayashi T, Zhou L, Nagahama Y. Molecular Cloning and Gene Expression of Foxl2 in the Nile Tilapia, Oreochromis Niloticus. Biochem Biophys Res Commun (2004) 320(1):83-9. doi: 10.1016/j.bbrc.2004.05.133

27. Wang DS, Kobayashi T, Zhou LY, Paul-Prasanth B, Ijiri S, Sakai F, et al. Foxl2 Up-Regulates Aromatase Gene Transcription in a Female-Specific Manner by Binding to the Promoter as Well as Interacting With Ad4 Binding Protein/ Steroidogenic Factor 1. Mol Endocrinol (Baltimore Md) (2007) 21(3):712-25. doi: 10.1210/me.2006-0248

28. Wang DS, Zhou LY, Kobayashi T, Matsuda M, Shibata Y, Sakai F, et al. Doublesex- and Mab-3-Related Transcription Factor-1 Repression of Aromatase Transcription, a Possible Mechanism Favoring the Male Pathway in Tilapia. Endocrinology (2010) 151(3):1331-40. doi: 10.1210/ en.2009-0999

29. Ijiri S, Kaneko H, Kobayashi T, Wang DS, Sakai F, Paul-Prasanth B, et al. Sexual Dimorphic Expression of Genes in Gonads During Early Differentiation of a Teleost Fish, the Nile Tilapia Oreochromis Niloticus. Biol Reprod (2008) 78(2):333-41. doi: 10.1095/biolreprod.107.064246

30. Yamaguchi T, Yamaguchi S, Hirai T, Kitano T. Follicle-Stimulating Hormone Signaling and Foxl2 Are Involved in Transcriptional Regulation of Aromatase Gene During Gonadal Sex Differentiation in Japanese Flounder, Paralichthys Olivaceus. Biochem Biophys Res Commun (2007) 359(4):935-40. doi: 10.1016/ j.bbrc.2007.05.208

31. Zhang X, Li M, Ma H, Liu X, Shi H, Li M, et al. Mutation of Foxl2 or Cyp19a1a Results in Female to Male Sex Reversal in XX Nile Tilapia. Endocrinology (2017) 158(8):2634-47. doi: 10.1210/en.2017-00127

32. Li MH, Yang HH, Li MR, Sun YL, Jiang XL, Xie QP, et al. Antagonistic Roles of Dmrt1 and Foxl2 in Sex Differentiation via Estrogen Production in Tilapia as Demonstrated by TALENs. Endocrinology (2013) 154(12):4814-25. doi: 10.1210/en.2013-1451

33. Yang YJ, Wang Y, Li Z, Zhou L, Gui JF. Sequential, Divergent, and Cooperative Requirements of Foxl2a and Foxl2b in Ovary Development and Maintenance of Zebrafish. Genetics (2017) 205(4):1551-72. doi: 10.1534/genetics.116.199133

34. Fukada S, Tanaka M, Matsuyama M, Kobayashi D, Nagahama Y. Isolation, Characterization, and Expression of cDNAs Encoding the Medaka (Oryzias latipes) Ovarian Follicle Cytochrome P-450 Aromatase. Mol Reprod Dev (1996) 45(3):285-90. doi: 10.1002/(SICI)1098-2795(199611)45:3<285::AIDMRD4>3.0.CO;2-O

35. Watanabe M, Tanaka M, Kobayashi D, Yoshiura Y, Oba Y, Nagahama Y. Medaka (Oryzias latipes) FTZ-F1 Potentially Regulates the Transcription of P-450 Aromatase in Ovarian Follicles: cDNA Cloning and Functional Characterization. Mol Cell Endocrinol (1999) 149(1-2):221-8. doi: 10.1016/ s0303-7207(99)00006-4

36. Nakamoto M, Wang DS, Suzuki A, Matsuda M, Nagahama Y, Shibata N. Daxl Suppresses P450arom Expression in Medaka Ovarian Follicles. Mol Reprod Dev (2007) 74(10):1239-46. doi: 10.1002/mrd.20689

37. Quek SI, Chan WK. Transcriptional Activation of Zebrafish Cyplla1 Promoter Is Dependent on the Nuclear Receptor Ff1b. J Mol Endocrinol (2009) 43(3):121-30. doi: 10.1677/JME-09-0029 
38. Luo X, Ikeda Y, Parker KL. A Cell-Specific Nuclear Receptor Is Essential for Adrenal and Gonadal Development and Sexual Differentiation. Cell (1994) 77 (4):481-90. doi: 10.1016/0092-8674(94)90211-9

39. Shinoda K, Lei H, Yoshii H, Nomura M, Nagano M, Shiba H, et al. Developmental Defects of the Ventromedial Hypothalamic Nucleus and Pituitary Gonadotroph in the Ftz-F1 Disrupted Mice. Dev Dynamics: an Off Publ Am Assoc Anatomists (1995) 204(1):22-9. doi: 10.1002/aja.1002040104

40. Meeks JJ, Crawford SE, Russell TA, Morohashi K, Weiss J, Jameson JL. Dax1 Regulates Testis Cord Organization During Gonadal Differentiation. Dev (Cambridge England) (2003) 130(5):1029-36. doi: 10.1242/dev.00316

41. Baron D, Houlgatte R, Fostier A, Guiguen Y. Expression Profiling of Candidate Genes During Ovary-to-Testis Trans-Differentiation in Rainbow Trout Masculinized by Androgens. Gen Comp Endocrinol (2008) 156(2):36978. doi: 10.1016/j.ygcen.2008.01.016

42. Herpin A, Schartl M. Dmrt1 Genes at the Crossroads: A Widespread and Central Class of Sexual Development Factors in Fish. FEBS J (2011) 278 (7):1010-9. doi: 10.1111/j.1742-4658.2011.08030.x

43. Kobayashi T, Matsuda M, Kajiura-Kobayashi H, Suzuki A, Saito N, Nakamoto M, et al. Two DM Domain Genes, DMY and DMRT1, Involved in Testicular Differentiation and Development in the Medaka, Oryzias Latipes. Dev Dynamics: an Off Publ Am Assoc Anatomists (2004) 231(3):518-26. doi: $10.1002 /$ dvdy.20158

44. Raghuveer K, Garhwal R, Wang DS, Bogerd J, Kirubagaran R, Rasheeda MK, et al. Effect of Methyl Testosterone- and Ethynyl Estradiol-Induced Sex Differentiation on Catfish, Clarias Gariepinus: Expression Profiles of DMRT1, Cytochrome P450aromatases and 3 Beta-Hydroxysteroid Dehydrogenase. Fish Physiol Biochem (2005) 31(2-3):143-7. doi: 10.1007/s10695-006-0016-3

45. Zhang $X$, Zha J, Wang Z. Influences of 4-Nonylphenol on Doublesex- and mab-3-Related Transcription Factor 1 Gene Expression and Vitellogenin mRNA Induction of Adult Rare Minnow (Gobiocypris rarus). Environ Toxicol Chem (2008) 27(1):196-205. doi: 10.1897/07-067.1

46. Fernandino JI, Hattori RS, Shinoda T, Kimura H, Strobl-Mazzulla PH, Strüssmann CA, et al. Dimorphic Expression of dmrtl and cyp19a1 (Ovarian Aromatase) During Early Gonadal Development in Pejerrey, Odontesthes Bonariensis. Sexual Development: Genet Mol Biol Evol Endocrinol Embryol Pathol Sex Determination Differentiation (2008) 2 (6):316-24. doi: 10.1159/000195681

47. Schulz RW, Bogerd J, Male R, Ball J, Fenske M, Olsen LC, et al. EstrogenInduced Alterations in amh and dmrtl Expression Signal for Disruption in Male Sexual Development in the Zebrafish. Environ Sci Technol (2007) 41 (17):6305-10. doi: 10.1021/es070785+

48. Vizziano-Cantonnet D, Baron D, Mahè S, Cauty C, Fostier A, Guiguen Y. Estrogen Treatment Up-Regulates Female Genes But Does Not Suppress All Early Testicular Markers During Rainbow Trout Male-to-Female Gonadal Transdifferentiation. J Mol Endocrinol (2008) 41(5):277-88. doi: 10.1677/ JME-08-0039

49. Cui Z, Liu Y, Wang W, Wang Q, Zhang N, Lin F, et al. Genome Editing Reveals Dmrtl as an Essential Male Sex-Determining Gene in Chinese Tongue Sole (Cynoglossus Semilaevis). Sci Rep (2017) 7:42213. doi: 10.1038/srep42213

50. Webster KA, Schach U, Ordaz A, Steinfeld JS, Draper BW, Siegfried KR. Dmrtl is Necessary for Male Sexual Development in Zebrafish. Dev Biol (2017) 422(1):33-46. doi: 10.1016/j.ydbio.2016.12.008
51. Masuyama H, Yamada M, Kamei Y, Fujiwara-Ishikawa T, Todo T, Nagahama Y, et al. Dmrt1 Mutation Causes a Male-to-Female Sex Reversal After the Sex Determination by Dmy in the Medaka. Chromosome Res (2012) 20(1):163-76. doi: 10.1007/s10577-011-9264-x

52. Nanda I, Kondo M, Hornung U, Asakawa S, Winkler C, Shimizu A, et al. A Duplicated Copy of DMRT1 in the Sex-Determining Region of the Y Chromosome of the Medaka, Oryzias latipes. Proc Natl Acad Sci USA (2002) 99(18):11778-83. doi: 10.1073/pnas.182314699

53. Siegfried KR. In Search of Determinants: Gene Expression During Gonadal Sex Differentiation. J Fish Biol (2010) 76(8):1879-902. doi: 10.1111/j.10958649.2010.02594.x

54. Takehana Y, Matsuda M, Myosho T, Suster ML, Kawakami K, Shin-I T, et al. CoOption of Sox 3 as the Male-Determining Factor on the Y Chromosome in the Fish Oryzias Dancena. Nat Commun (2014) 5:4157. doi: 10.1038/ncomms5157

55. Huang W, Zhou L, Li Z, Gui JF. Expression Pattern, Cellular Localization and Promoter Activity Analysis of Ovarian Aromatase (Cyp19a1a) in Protogynous Hermaphrodite Red-Spotted Grouper. Mol Cell Endocrinol (2009) 307(12):224-36. doi: 10.1016/j.mce.2009.04.003

56. Rajakumar A, Senthilkumaran B. Sox3 Binds to $11 \beta$-Hydroxysteroid Dehydrogenase Gene Promoter Suggesting Transcriptional Interaction in Catfish. J Steroid Biochem Mol Biol (2016) 158:90-103. doi: 10.1016/ j.jsbmb.2016.01.003

57. Diotel N, Le Page Y, Mouriec K, Tong SK, Pellegrini E, Vaillant C, et al. Aromatase in the Brain of Teleost Fish: Expression, Regulation and Putative Functions. Front Neuroendocrinol (2010) 31(2):172-92. doi: 10.1016/ j.yfrne.2010.01.003

58. Cheshenko K, Brion F, Le Page Y, Hinfray N, Pakdel F, Kah O, et al. Expression of Zebra Fish Aromatase cyp19a and cyp19b Genes in Response to the Ligands of Estrogen Receptor and Aryl Hydrocarbon Receptor. Toxicol Sci: an Off J Soc Toxicol (2007) 96(2):255-67. doi: 10.1093/toxsci/kfm003

59. Piferrer F. Epigenetics of Sex Determination and Gonadogenesis. Dev Dynamics: an Off Publ Am Assoc Anatomists (2013) 242(4):360-70. doi: $10.1002 /$ dvdy.23924

Conflict of Interest: The authors declare that the research was conducted in the absence of any commercial or financial relationships that could be construed as a potential conflict of interest.

Publisher's Note: All claims expressed in this article are solely those of the authors and do not necessarily represent those of their affiliated organizations, or those of the publisher, the editors and the reviewers. Any product that may be evaluated in this article, or claim that may be made by its manufacturer, is not guaranteed or endorsed by the publisher.

Copyright (C) 2022 Sharma, Purohit, Kothiyal, Negi and Bhattacharya. This is an open-access article distributed under the terms of the Creative Commons Attribution License (CC BY). The use, distribution or reproduction in other forums is permitted, provided the original author(s) and the copyright owner(s) are credited and that the original publication in this journal is cited, in accordance with accepted academic practice. No use, distribution or reproduction is permitted which does not comply with these terms. 